\title{
Asymptomatic Urinary Tract infection in Pregnant and Non-pregnant Women in the Limbe Health District of Cameroon: A Phenotypic and Biochemical analytic study
}

Chantal Emade Nkwelle

2. Referral Laboratory, Bota District Hospital, Limbe

Jane-Francis Tatah Kihla Akoachere ( $\nabla$ jakoachere@yahoo.com )

1. Department of Microbiology and Parasitology, Faculty of Science, University of Buea, Box 63, Buea Lucy Mande Ndip

3. Laboratory for Emerging Infectious Diseases, Faculty of Science, University of Buea, Box 63, Buea,

\section{Franklin Ajoeh Nzang}

2. Referral Laboratory, Bota District Hospital, Limbe

Seraphine Foto Esemu

3. Laboratory for Emerging Infectious Diseases, Faculty of Science, University of Buea, Box 63, Buea, Roland Ndip Ndip

3. Laboratory for Emerging Infectious Diseases, Faculty of Science, University of Buea, Box 63, Buea,

\section{Research Article}

Keywords: Asymptomatic urinary tract infection, pregnant and non-pregnant women, biochemical indicators, creatinine, antibiotics susceptibility

Posted Date: January 18th, 2022

DOI: https://doi.org/10.21203/rs.3.rs-1166457/v1

License: (c) (1) This work is licensed under a Creative Commons Attribution 4.0 International License. Read Full License 


\section{Abstract \\ Background}

Asymptomatic bacteriuria in pregnancy is associated with significant maternal and fetal risks. However, there seem to be a dearth of information of its prevalence in our community. This study investigated the prevalence of the etiology and antibiotic susceptibility profile of bacterial agents incriminated in urinary tract infection (UTI) in pregnant and non- pregnant women. The association between leukocyte esterase, nitrite, serum creatinine and asymptomatic urinary tract infection (UTI) was assessed.

\section{Methods}

A total of 150 urine and blood samples were collected (75 pregnant and 75 non-pregnant) and analyzed using standard microbiological and clinical chemistry methods for detection of isolates and their antibiotic sensitivity and serum creatinine level, respectively. Data obtained was analyzed using the SPSS data package; the Chi-square $\left(\mathrm{X}^{2}\right)$ test was used to examine significant differences at $5 \%$ significance level.

\section{Results}

The overall prevalence of asymptomatic UTI was 30\%, while the prevalence in pregnant and non-pregnant women was $29.3 \%$ and $30.7 \%$, respectively. Gram positive organisms were more prevalent (77.6\%) than gram negative organisms (22.4\%). The most prevalent organism was $S$. aureus (20.1\%), while Enterococci (2.1\%) was the least prevalent. No statistically significant association existed between serum creatinine and asymptomatic UTI. Leukocyte esterase was a common indicator for UTI and was statistically significant in non-pregnant women ( $\mathrm{P}=0.009)$. Ciprofloxacin, ceftriaxone and amoxiclav were the most effective antibiotics (100\%) against most isolates. However, some isolates demonstrated high resistance to cefixime and ampicillin, respectively $(100 \%)$.

\section{Conclusion}

Asymptomatic UTI is a problem in pregnant and non-pregnant women in our environment, with a majority of the cases attributed to Gram positive bacteria. Resistance to some of the antibiotics currently employed in the treatment of this infection was remarkable. The use of biochemical indicators in the diagnosis of UTI in our environment should be done with caution. These findings, therefore, have epidemiological and clinical significance, and calls for more attention in the management of UTI.

\section{Background}

Bacteriuria is the presence and growth of bacteria in the urinary tract. This may lead to urinary tract infection (UTI) [1]. UTI is a predisposing factor to adverse pregnancy outcomes and presents with some effects on renal function [2]. Hormonal and immunological changes in pregnancy, including high level of progesterone secretion, which could lead to stasis and decrease immunity are contributing factors to UTI [3]. Asymptomatic bacteriuria occurs in 2 to $7 \%$ of pregnant women. However, this prevalence can be up to $30 \%$ in developing countries [4]. A study on bacteriuria in pregnant women in three hospitals in Douala, Cameroon reported a significant prevalence of symptomatic bacteriuria of $9.9 \%$ and asymptomatic bacteriuria of $5.7 \%$ [1]. In another study in Buea, Cameroon, the prevalence of bacteriuria in pregnant women was $23.5 \%$ and $7.8 \%$ [5], for symptomatic and asymptomatic cases, respectively.

Escherichia coli and Staphylococcus saprophyticus account for about 80\% of community-acquired UTI [6]. Other Gram-negative pathogens, including Pseudomonas spp, Enterobacter spp, Citrobacter spp, and Klebsiella spp, are also incriminated in urinary tract infection [6]. Gram-positive bacteria, including Enterococcus spp and Staphylococcus spp [7] can cause nosocomial UTI due to selective pressure from the antimicrobial agents used in hospitalized patients. The relatively high prevalence of UTIs during pregnancy, and the significant consequences for women and the pregnancy outcome justify screening of pregnant women for UTIs [8].

In a urinalysis, the presence of leukocyte esterase suggests the presence of white blood cells while nitrite test detects the products of nitrate reductase, an enzyme produced by many gram negative bacteria. Serum creatinine concentration remains the standard, single-point assessment for kidney function in pregnant populations, yet a normal range in pregnancy has not been established [9]. However, routine analysis of urine in pregnant women is generally limited to just two parameters; glucose and albumin; whereas UTI and kidney malfunction are certainly dangers to pregnancy as it may affect the general health of the mother and fetus in the future.

Biochemical indicators of UTI such as the presence of leucocyte esterase and nitrite are obviously rapid laboratory procedures, which can be incorporated into the testing panel of pregnant women in resource limited settings such as Cameroon, where these tests are available and affordable. Uncomplicated UTIs are generally self-limiting, but the social stigma associated to UTI is of concern to patients and, as such, they engage in unorthodox treatment or self-medication using antibiotics [10].

Without treatment, up to 20 to $30 \%$ of pregnant women with asymptomatic bacteriuria will develop a symptomatic urinary tract infection [11]. In a previous study [12], E. coli, S. aureus, Beta haemolytic Streptococci, coagulase negative Staphylococci and Group B Streptococci were reported to be 100\% susceptible to nitrofurantoin. In another study, E. coli reported $91.7 \%$ and $88.3 \%$ susceptibility to ciprofloxacin and ceftriaxone, respectively [8]. Chloramphenicol was also found to be successful in the treatment of UTI, being $100 \%$ effective against Klebsiella pneumoniae, Enterobacter aerogenes, and E. coli [13].

Page 2/12 
Bacterial resistance to antibiotics is one of the most challenging global health threats faced in modern medicine, and resistance of urinary tract pathogens has been reported to increase worldwide with a pattern which may vary over short periods, and depends on site of isolation and environmental conditions [14]. Clinicians are challenged in selecting appropriate treatment due to increase antibiotic resistance by these pathogens $[15,16]$. Studies have demonstrated geographic variation in etiologic characteristics of UTI and their resistance patterns to antibiotics [10].

In our environment, urine culture is not routinely done for antenatal patients. The dip stick test is the most widely used method for assessing urine in pregnant women. Consequently, the microbiological picture of such urine specimen cannot be fully ascertained, as the strip cannot quantify the extent of infection as well as provide indication for antimicrobial chemotherapy. To ensure appropriate therapy for these infections, current knowledge of the etiologic agents, their biochemical indicators and antibiotic susceptibility profile of isolates are necessary for improved intervention. The aim of this study was to isolate and identify the bacterial agents causing asymptomatic UTI in pregnant and non-pregnant women in Limbe Health District, assess their association with certain biochemical indicators, serum creatinine level and their antibiotic susceptibility profile.

\section{Methods Study Design}

This was a hospital based cross sectional study, in which asymptomatic, 75 pregnant and 75 non-pregnant women, aged 13-44 years consulting in some health care facilities in the Limbe Health District, were investigated for asymptomatic UTI and kidney function. It was based on laboratory investigations with urine and blood samples obtained from the women. Data on sociodemographic characteristics of participants was obtained using a questionnaire.

\section{Study site and participants}

This study was conducted in health facilities representing the key health areas in the Limbe Health District, along the coast line of South West Region, Cameroon. Limbe is a cosmopolitan town, made of people from different tribes, cultures and background. This district has a population of about 118,210 inhabitants with a total of 60,228 women and 8,712 women of child bearing age [17]. Most of these women are sexually active, under educated, and make use of public toilets. Those who live around the beaches mostly use seawater and springs for personal hygiene, which can predispose them to UTIs.

\section{Ethical Considerations}

All methods were carried out in accordance with relevant local and national regulations. An administrative authorization was obtained from the South West Regional Delegation of Public Health; ethical approval obtained from the Institutional Review Board (IRB), Faculty of Heath Sciences, University of Buea with reference number 2020/1038-12/UB/SG/IRB/FHS. A verbal authorization was obtained from the different participating health facilities. An informed consent was signed by all subjects and an informed consent by parent or guardian of subjects less than 21 years.

\section{Sample Collection}

Samples were collected from all pregnant and non-pregnant women who gave their consent, without obvious clinical signs of UTI and/or kidney malfunction, and were not on antibiotics for the last 72 hours. Urine and blood samples were collected for culture, urine dipstick, and creatinine tests respectively. About fifteen milliliters $(15 \mathrm{~mL})$ of clean-catch midstream urine was collected in sterile, dry, wide-mouth, leak-proof container. The women were instructed to clean the area around the urethral opening with absorbent paper, and collect urine while holding the labia apart. Five milliliters of blood were collected aseptically from each study participant by venipuncture and transferred to a sterile vacutainer tube without anticoagulant. Samples were transported on ice to the Microbiology Laboratory (urine) and to the Clinical Chemistry Laboratory (blood), of the District Hospital, Limbe, for analysis. In situations where delay was anticipated before analysis, samples were preserved in a refrigerator at $2-8^{\circ} \mathrm{C}$ for at most 4 hours (urine samples) and 24 hours (blood).

\section{Determination of Creatinine Level}

Blood samples were allowed to clot by leaving them undisturbed at room temperature for 45 min, dislodged and centrifuged between $2200-2500$ rpm (revolution per minute) for 10 minutes and approximately $2 \mathrm{~mL}$ of serum harvested. Creatinine test was performed, using the creatinine test kit (Cypress Diagnostic, Belgium) as described by Cheesbrough (2000) [18], and according to manufacturer's instruction. Briefly, reagent 1 (R1) and reagent 2 (R2) were reconstituted in equal proportion for use within seven days, stored at $2-8{ }^{\circ} \mathrm{C}$. Quality control (QC) runs of normal and pathological commercial control sera (CYPRESS DIAGNOSTICS Belgium) were performed daily before analysis. Briefly, $1000 \mu / \mathrm{L}$ of the reagent was pipetted into each of five sterile glass test tubes and labeled as follows: test tube 1 (blank), test tube 2 (standard), test tube 3 (pathological control), test tube 4 (normal control) and test tube 5 (subject code). Exactly $100 \mu / L$ of the standard, pathological control, normal control and $100 \mu / L$ of participants' serum were added sequentially into respective reagent tubes. The content of each tube was mixed, its absorbance and concentration measured and recorded by spectrophotometry (Sinothinker China, at wavelength $630 \mathrm{~nm}$ ) before reconstituting the next tube. Results for normal and pathological controls were recorded and verified to fall within $+/-2 S D$ before samples were tested, results accepted and recorded.

\section{Urine Dipstick test}


Urine samples were tested with the rapid urine dipstick (ACON Laboratories, Inc., China) by dipping the strip into urine and results for leucocyte esterase and nitrite obtained within 30 seconds to 1 minute [19]. Strips were dipped in the well-mixed urine for no longer than four seconds and excess urine, along the rim of strips, wiped. After 1 minute, the colour change in the strips was compared with the color scales provided with the kit. A violet colour produced was considered as leucocyte esterase positive, and pink colour as nitrate positive. Colour changes appearing only along the edges of the test patches or developing after more than 2 minutes were considered negative. Most gram negative uropathogens produce nitrate reducing enzymes that reduce nitrate to nitrites. Nitrite reacts with an amine impregnated on the dipstick pad to form a diazonium compound resulting in a pink colour reaction within 60 seconds. An enzyme produced by inflammatory cells, leukocyte esterase, reacts with the chloroacetate stain impregnated in a dipstick pad resulting in an iodoxyl moiety that is oxidized by room air and produces a colour change in 1-2 minutes.

\section{Urine culture test}

Following standard procedure, exactly $0.01 \mathrm{~mL}$ of urine samples were inoculated aseptically on CLED agar (HiMedia Laboratories Pvt. Ltd.,India) by streaking technique. The culture plates were incubated aerobically at $37^{\circ} \mathrm{C}$ for $24-48$ hours, after which they were observed for growth. Colonies were counted and the counts multiplied by 100 to have the Colony Forming Units per milliliter (CFU/mL) of urine. Plates with growth or colonies less than $1000 \mathrm{CFU} / \mathrm{mL}$ were incubated for another 24 hours. Only plates with counts $>10^{5} \mathrm{CFU} / \mathrm{mL}$ were considered as significant bacteriuria [20]. The isolates were further identified on the basis of colonial morphology, cultural characteristics, Gram's staining and a battery of biochemical reactions $[1,5]$.

\section{Antimicrobial Susceptibility Testing}

The susceptibility pattern of isolates to antibiotics employed in the empiric treatment of UTI was studied. Antimicrobial susceptibility tests were performed on bacterial isolates from midstream urine using antimicrobial discs, according to Clinical and Laboratory Standards Institute (CLSI) on Muller Hinton agar [21].

Briefly, 2-3 colonies from the pure culture were suspended in a vial of $7 \mathrm{~mL}$ physiological saline to obtain a turbidity equivalent to $0.5 \mathrm{McFarland}$. A sterile swab was dipped into the suspension and excess moisture removed by pressing the swab against the side of the tube. The surface of Muellar-Hinton agar was swabbed completely and allowed to dry for about 5 minutes. The following antibiotics from Fluka Industry, United Kingdom, were used: Amoxiclav (30 $\mu \mathrm{g})$, Flucloxacillin $(5 \mu \mathrm{g})$, Ampicillin $(10 \mu \mathrm{g})$, Ceftriaxone $(30 \mu \mathrm{g})$, Cefixime $(5 \mu \mathrm{g})$, Levofloxacin $(5 \mu \mathrm{g})$, Ciprofloxacin $(30 \mu \mathrm{g})$, Ofloxacin $(5 \mu \mathrm{g})$ and Gentamicin $(10$ $\mu \mathrm{g})$. Antibiotic disks were placed on the agar keeping at least a distance of $24 \mathrm{~mm}$ between them. About 15 minutes after disks were applied, the plates were inverted and incubated at $37^{\circ} \mathrm{C}$ for $18-24$ hours. Results were reported as sensitive or resistant based on the specific diameter of zone of inhibition for the different antibiotics [22].

\section{Statistical analysis}

Data obtained was entered into excel spread sheet and analysed using SPSS statistical package. Descriptive statistics was used to determine the prevalence of asymptomatic UTI. The frequencies, percentages and measures of central tendencies were obtained. The Pearson's Chi-square was used to determine if there was correlation between the different variables. To compare the means, the student t-test was used. Statistical significance was taken at the level $p<$ 0.05 .

\section{Results}

\section{Socio-demographic Characteristics}

A total of 150 women were enrolled in this study with age range of 13-44 years and a mean (standard deviation) of 26.97 ( \pm 6.17 ) years. Seventy-five pregnant women with age range 16-38 years and a mean age (standard deviation) of 26.53 ( \pm 5.16 ) years, and 75 non-pregnant women with age range $13-44$ years and a mean age (standard deviation) of $27.41( \pm 7.05)$ years participated in this study. Among the pregnant subjects, $28(37.3 \%)$ were between the ages 13-24 years, 44(58.7\%) between 25-34 years, and 3 (4.0\%) between 35-38 years (Table 1). Amongst the non-pregnant cases, 26 (34.7 \%) were between the ages 13-24 years, and 12 (16.0 \%) between 35-44 years. Based on parity, 56 (37.3\%), 38 (25.3 \%), and 56 (37.3 \%) were nulliparous, mono parous, multiparous, respectively (Table 1$)$.

Among the 75 pregnant subjects, $36(48.0 \%), 32(42.7 \%)$ and $7(9.3 \%)$ were in their $3^{\text {rd }}, 2^{\text {nd }}$ and $1^{\text {st }}$ trimester of pregnancy, respectively. Overall, $39(26.0 \%)$ of study subjects had a history of previous urinary tract infection. This comprised 20 (26.7\%) and 19 (25.3\%) of the pregnant and non-pregnant women, respectively.

Table 1: Socio-demographic characteristics of study participants 


\begin{tabular}{|c|c|c|c|}
\hline Characteristic & $\begin{array}{l}\text { Pregnant } \\
\mathrm{n}(\%)\end{array}$ & $\begin{array}{l}\text { Non pregnant } \\
\text { n (\%) }\end{array}$ & TOTAL \\
\hline \multicolumn{4}{|c|}{ Most sexually active Age group } \\
\hline $13-24$ & $28(37.3)$ & $26(34.7)$ & $54(36.0)$ \\
\hline $25-34$ & $44(58.7)$ & $37(49.3)$ & $81(54.0)$ \\
\hline $35-44$ & $3(4.0)$ & $12(16.0)$ & $15(10.0)$ \\
\hline \multicolumn{4}{|l|}{ Residence } \\
\hline Sea port & $3(4.0)$ & $4(5.3)$ & $7(4.7)$ \\
\hline Town & $47(62.7)$ & $48(64.0)$ & $95(63.3)$ \\
\hline West coast & 25(33.3) & 23(30.7) & $48(32.0)$ \\
\hline \multicolumn{4}{|c|}{ Number of children } \\
\hline 0 & 25(33.3) & $31(41.3)$ & $56(37.3)$ \\
\hline 1 & $23(30.7)$ & $15(20.0)$ & $38(25.3)$ \\
\hline 2 & 16(21.3) & $17(22.7)$ & $33(22.0)$ \\
\hline 3 & 10(13.3) & 10(13.3) & $20(13.3)$ \\
\hline$>4$ & $1(1.3)$ & $2(2.6)$ & $3(2.0)$ \\
\hline \multicolumn{4}{|c|}{ Trimester of gestation } \\
\hline $1^{\text {st }}$ & $7(9.3)$ & / & $7(9.3)$ \\
\hline $2^{\text {nd }}$ & $32(42.7)$ & / & $32(42.7)$ \\
\hline $3^{\text {rd }}$ & $36(48.0)$ & / & $36(48.0)$ \\
\hline
\end{tabular}

\section{Prevalence of asymptomatic UTI}

The overall asymptomatic UTI prevalence in the study population was $30 \%$. The prevalence in non-pregnant and pregnant women was $29.3 \%$ and $30.7 \%$, respectively (Table 2). However, the difference was not statistically significant $(P=0.859)$.

Table 2: Distribution of asymptomatic UTI cases across study participant

\begin{tabular}{|llll|}
\hline \multicolumn{3}{|l|}{ Asymptomatic UTI } & \\
& & & \\
& Pregnant & & \\
& $\mathbf{n}(\%)$ & Non-Pregnant & Total \\
& & $\mathbf{n}(\%)$ & $\mathbf{n}(\%)$ \\
\hline Negative & $52(69.3 \%)$ & $53(70.7 \%)$ & $105(70 \%)$ \\
\hline Positive & $23(\mathbf{3 0 . 7 \% )}$ & $22(\mathbf{2 9 . 3 \% )}$ & $45(30 \%)$ \\
& 75 & 75 & 150 \\
\hline & & & Chi square $=0.032$ \\
& & & P-value $=0.859$ \\
\hline
\end{tabular}

\section{Etiologic profile of asymptomatic UTI}

Among the identified isolates, S. aureus recorded a dominant $20.1 \%$ prevalence, with $17.4 \%$ (4) and $22.8 \%$ (5) in pregnant and non-pregnant women, respectively. This was followed by $S$. saprophyticus with an overall prevalence of $15.4 \%$, higher in pregnant women $(26.2 \%, 6 / 23)$ than in non-pregnant women $(4.5 \%, 1 / 22)$. Escherichia coli had a prevalence of $11.1 \%(5)$ occurring more $(13.6 \%, 3 / 22)$ in non-pregnant than in pregnant women $(8.7 \%, 2 / 23)$. Lactobacillus and Enterococci were detected only in pregnant women, each with a prevalence of $2.2 \%$ (1). Unidentified gram positive rods were observed with 
a prevalence of $31.2 \%$. Their prevalence in this study population was similar in pregnant $30.5 \%$ (7) and in non-pregnant $31.9 \%$ (7) women. Shigella species (2.3\%) and Citrobacter diversus (2.3\%) were detected only in non-pregnant women. There was no significant difference of bacterial isolates in pregnant and non-pregnant women $(\mathrm{P}=0.482)$ (Table 3$)$.

Table 3: Prevalence of bacterial pathogens in cases of asymptomatic UTI

\begin{tabular}{|llll|}
\hline Bacterial Isolates & $\begin{array}{l}\text { Pregnant } \\
\mathbf{n}(\%)\end{array}$ & $\begin{array}{l}\text { Non-pregnant } \\
\mathbf{n}(\%)\end{array}$ & $\begin{array}{l}\text { Total } \\
\mathbf{n}(\%)\end{array}$ \\
\hline Gram positive & & & \\
\hline Enterococci & $1(4.3)$ & $0(0.0)$ & $1(2.1)$ \\
\hline Lactobacillus & $1(4.3)$ & $0(0.0)$ & $1(2.1)$ \\
\hline Positive rods & $7(30.5)$ & $7(31.9)$ & $14(31.2)$ \\
\hline S. aureus & $4(17.4)$ & $5(22.8)$ & $9(20.1)$ \\
\hline S. epidermidis & $1(4.3)$ & $2(9.1)$ & $3(6.7)$ \\
\hline S. saprophyticus & $6(26.2)$ & $1(4.5)$ & $7(15.4)$ \\
\hline Gram negative & & & \\
\hline Neisseria gonorrhoeae & $1(4.3)$ & $2(9.1)$ & $3(6.7)$ \\
\hline Shigella species & $0(0.0)$ & $1(4.5)$ & $1(2.3)$ \\
\hline E. coli & $2(8.7)$ & $3(13.6)$ & $5(11.1)$ \\
\hline Citrobacter diversus & $0(0.0)$ & $1(4.5)$ & $1(2.3)$ \\
\hline Total & $23(30.7)$ & $22(29.3)$ & $45(30.0)$ \\
\hline & & & Phi square= 8.531 \\
\hline
\end{tabular}

\section{Association between leukocyte esterase/nitrite and Asymptomatic UTI}

There was no significant association between leukocyte esterase and nitrite with asymptomatic UTI in pregnant women. In non-pregnant women, leukocyte esterase was significantly associated to asymptomatic UTI $(P=0.009)$ (Table 4). Furthermore, women who presented with positive leukocyte esterase were $25.3 \%$ (19) and $9.3 \%$ (7) pregnant and non-pregnant, respectively.

Table 4: Association between leucocyte esterase and asymptomatic UTI

\begin{tabular}{|lll|}
\hline \multicolumn{3}{|c|}{ Asymptomatic UTI } \\
\hline Leukocyte (cells/uL) & Pregnant $(n=75)$ & Non-pregnant $(n=75)$ \\
\hline $0(0)$ & $56(74.7)$ & $68(90.7)$ \\
\hline $15(+1)$ & $11(14.7)$ & $2(2.7)$ \\
\hline $50(+2)$ & $0(0)$ & $1(1.3)$ \\
\hline $70(+3)$ & $7(9.3)$ & $3(4.0)$ \\
\hline $125(+4)$ & $1(1.3)$ & $1(1.3)$ \\
\hline Total for positive Leukocyte & $19(25.3)$ & $7(9.3)$ \\
& Chi square= 1.215 & Chi square= 13.492 \\
& P value= 0.749 & P value= $0.009 *$ \\
\hline
\end{tabular}

Nitrite was only present in a single case 1 (4.5\%) (non-pregnant) and had no statistically significant association $(P=0.118)(T a b l e ~ 5)$.

Table 5: Association between nitrite and Asymptomatic UTI 


\begin{tabular}{|lll|}
\hline \multicolumn{3}{|c|}{ Asymptomatic UTI } \\
\hline & Pregnant $(\mathbf{n}=75)$ & Non-pregnant $(\mathbf{n}=75)$ \\
\hline Nitrite & & \\
\hline Negative & $75(100)$ & $74(95.5)$ \\
\hline Positive & $0(0)$ & $1(4.5)$ \\
\hline Total & $75(100)$ & $75(100)$ \\
\hline & Chi square, P-value & Chi square $=2.442$, \\
& Not applicable & P value $=0.118$ \\
\hline
\end{tabular}

\section{Relationship between Asymptomatic UTI and serum creatinine}

Abnormal creatinine levels ( $\geq 1.4 \mathrm{mg} / \mathrm{dL}$ ) were found more in pregnant women 10(13.3\%) than in non-pregnant women $9(12.0 \%)$. However, there was no statistically significant association between serum creatinine level and asymptomatic UTI in pregnant $(P=0.154)$ and non-pregnant women $(P=0.617)(T a b l e$ $6)$.

Table 6: Association between asymptomatic UTI and serum creatinine

\begin{tabular}{|lll|}
\hline & \multicolumn{2}{c}{ Asymptomatic UTI } \\
\hline & Pregnant $(\mathbf{n}=75)$ & Non-pregnant $(\mathbf{n}=\mathbf{7 5})$ \\
\hline Abnormal creatinine & $10(13.3)$ & $9(12.0)$ \\
Normal creatinine & $65(86.7)$ & $66(88.0)$ \\
& & \\
Totals & $75(100)$ & $75(100)$ \\
& Chi square $=2.028$, & Chi square $=0.249$, \\
& P-value $=0.154$ & P-value $=0.617$ \\
\hline
\end{tabular}

\section{Antimicrobial Sensitivity}

Enterococci, Lactobacilli, S. aureus, Citrobacter diversus and gram positive rods were markedly (100\%) susceptible to ceftriaxone. Neisseria gonorrhoeae, Citrobacter diversus, Shigella species, gram positive rods and Enterococci, S. epidermidis were markedly susceptible (100\%) to ciprofloxacin and amoxiclav, respectively. N. gonorrhoeae, S. aureus, and S. epidermidis were moderately susceptible with $66.7 \%, 88.9 \%$ and $66.7 \%$ to ceftriaxone, respectively. E. coli, S. aureus and S. epidermidis were also moderately susceptible with $80 \%, 77.8 \%$ and $66.7 \%$ to ciprofloxacin, respectively. Most isolates were markedly resistant (100\%) to cefixime, ampicillin, gentamicin and flocoxacillin (Table7).

Table 7: Antimicrobial sensitivity reaction for all isolates 


\begin{tabular}{|c|c|c|c|c|c|c|c|c|c|c|c|c|c|c|}
\hline \multirow[b]{3}{*}{$\begin{array}{l}\text { Antibiotic } \\
(\mu \mathrm{g})\end{array}$} & \multicolumn{14}{|l|}{ Isolate } \\
\hline & \multicolumn{2}{|l|}{$\begin{array}{l}\text { E. coli } \\
\mathrm{n}=5(\%)\end{array}$} & \multicolumn{2}{|c|}{ Enterrococci $n=1(\%)$} & \multicolumn{2}{|c|}{ Lactobacillus $\mathrm{n}=1(\%)$} & \multicolumn{2}{|c|}{$\begin{array}{l}\begin{array}{l}\text { Neisseria } \\
\text { gonomhoeae }\end{array} \\
\mathrm{n}=3(\%)\end{array}$} & \multicolumn{2}{|c|}{$\begin{array}{l}\text { Positive Rod } \\
\mathrm{n}=14(\%)\end{array}$} & \multicolumn{2}{|c|}{$\begin{array}{l}\text { S. aureus } \\
\mathrm{n}=9(\%)\end{array}$} & \multicolumn{2}{|c|}{$\begin{array}{l}\text { S. epidemidis } \\
\mathrm{n}=3(\%)\end{array}$} \\
\hline & $S$ & $\mathrm{R}$ & S & $\mathbf{R}$ & $S$ & $\mathrm{R}$ & $S$ & $\mathrm{R}$ & $S$ & $\mathrm{R}$ & $S$ & $\mathrm{R}$ & $S$ & $\mathrm{R}$ \\
\hline AMC 30 & $\begin{array}{l}2 \\
(40.0)\end{array}$ & $\begin{array}{l}3 \\
(60.0)\end{array}$ & $1(100)$ & $\begin{array}{l}0 \\
(0)\end{array}$ & $\begin{array}{l}0 \\
(0)\end{array}$ & $\begin{array}{l}1 \\
(100)\end{array}$ & $\begin{array}{l}1 \\
(33.3)\end{array}$ & $\begin{array}{l}2 \\
(66.7)\end{array}$ & $\begin{array}{l}9 \\
(64.3)\end{array}$ & $\begin{array}{l}5 \\
(35.7)\end{array}$ & $\begin{array}{l}1 \\
(11.1)\end{array}$ & $\begin{array}{l}8 \\
(88.9)\end{array}$ & $\begin{array}{l}3 \\
(100)\end{array}$ & $\begin{array}{l}0 \\
(0)\end{array}$ \\
\hline FXL 10 & $\begin{array}{l}0 \\
(0)\end{array}$ & $\begin{array}{l}5 \\
(100)\end{array}$ & $\begin{array}{l}0 \\
(0)\end{array}$ & $\begin{array}{l}1 \\
(100)\end{array}$ & $\begin{array}{l}0 \\
(0)\end{array}$ & $\begin{array}{l}1 \\
(100)\end{array}$ & $\begin{array}{l}0 \\
(0)\end{array}$ & $\begin{array}{l}3 \\
(100)\end{array}$ & $\begin{array}{l}4 \\
(28.6)\end{array}$ & $\begin{array}{l}10 \\
(71.4)\end{array}$ & $\begin{array}{l}3 \\
(33.3)\end{array}$ & $\begin{array}{l}6 \\
(66.7)\end{array}$ & $\begin{array}{l}0 \\
(0)\end{array}$ & $\begin{array}{l}3 \\
(100)\end{array}$ \\
\hline AMP 10 & $\begin{array}{l}0 \\
(0)\end{array}$ & $\begin{array}{l}5 \\
(100)\end{array}$ & $\begin{array}{l}0 \\
(0)\end{array}$ & $\begin{array}{l}1 \\
(100)\end{array}$ & $\begin{array}{l}0 \\
(0)\end{array}$ & $\begin{array}{l}1 \\
(100)\end{array}$ & $\begin{array}{l}0 \\
(0)\end{array}$ & $\begin{array}{l}3 \\
(100)\end{array}$ & $\begin{array}{l}4 \\
(28.6)\end{array}$ & $\begin{array}{l}10 \\
(71.4)\end{array}$ & $\begin{array}{l}1 \\
(11.1)\end{array}$ & $\begin{array}{l}8 \\
(88.9)\end{array}$ & $\begin{array}{l}0 \\
(0)\end{array}$ & $\begin{array}{l}3 \\
(100)\end{array}$ \\
\hline СТХ 30 & $\begin{array}{l}2 \\
(40.0)\end{array}$ & $\begin{array}{l}3 \\
(60.0)\end{array}$ & $\begin{array}{l}1 \\
(100)\end{array}$ & & $\begin{array}{l}1 \\
(100)\end{array}$ & $\begin{array}{l}0 \\
(0)\end{array}$ & $\begin{array}{l}2 \\
(66.7)\end{array}$ & $\begin{array}{l}1 \\
(33.3)\end{array}$ & $\begin{array}{l}8 \\
(100)\end{array}$ & & $\begin{array}{l}8 \\
(88.9)\end{array}$ & $\begin{array}{l}1 \\
(11.1)\end{array}$ & $\begin{array}{l}2 \\
(66.7)\end{array}$ & $\begin{array}{l}1 \\
\text { (33.3) }\end{array}$ \\
\hline CXM 5 & $\begin{array}{l}1 \\
(20.0)\end{array}$ & $\begin{array}{l}4 \\
(80.0)\end{array}$ & $\begin{array}{l}0 \\
(0)\end{array}$ & $\begin{array}{l}1 \\
(100)\end{array}$ & $\begin{array}{l}0 \\
(0)\end{array}$ & $\begin{array}{l}1 \\
(100)\end{array}$ & $\begin{array}{l}0 \\
(0)\end{array}$ & $\begin{array}{l}3 \\
(100)\end{array}$ & $\begin{array}{l}0 \\
(0)\end{array}$ & $\begin{array}{l}14 \\
(100)\end{array}$ & $\begin{array}{l}0 \\
(0)\end{array}$ & $\begin{array}{l}9 \\
(100)\end{array}$ & & $\begin{array}{l}3 \\
(100)\end{array}$ \\
\hline LEV 5 & $\begin{array}{l}3 \\
(60.0)\end{array}$ & $\begin{array}{l}2 \\
(40.0)\end{array}$ & $0(0)$ & $1(100)$ & $\begin{array}{l}0 \\
(0)\end{array}$ & $\begin{array}{l}1 \\
(100)\end{array}$ & $\begin{array}{l}1 \\
(33.3)\end{array}$ & $\begin{array}{l}2 \\
(66.7)\end{array}$ & $\begin{array}{l}4 \\
(28.6)\end{array}$ & $\begin{array}{l}10 \\
(71.4)\end{array}$ & $\begin{array}{l}3 \\
(33.3)\end{array}$ & $\begin{array}{l}6 \\
(66.7)\end{array}$ & $\begin{array}{l}0 \\
(0)\end{array}$ & $\begin{array}{l}3 \\
(100)\end{array}$ \\
\hline CIP 30 & $\begin{array}{l}4 \\
(80.0)\end{array}$ & $\begin{array}{l}1 \\
(20.0)\end{array}$ & $0(0)$ & $\begin{array}{l}1 \\
(100)\end{array}$ & $\begin{array}{l}0 \\
(0)\end{array}$ & $\begin{array}{l}1 \\
(100)\end{array}$ & $\begin{array}{l}3 \\
(100)\end{array}$ & $\begin{array}{l}0 \\
(0)\end{array}$ & $\begin{array}{l}14 \\
(100)\end{array}$ & $\begin{array}{l}0 \\
(0)\end{array}$ & $\begin{array}{l}7 \\
(77.8)\end{array}$ & $\begin{array}{l}2 \\
(22.2)\end{array}$ & $\begin{array}{l}2 \\
(66.7)\end{array}$ & $\begin{array}{l}1 \\
\text { (33.3) }\end{array}$ \\
\hline OFL 5 & $2(40.0)$ & $\begin{array}{l}3 \\
(60.0)\end{array}$ & $0(0)$ & $1(100)$ & $0(0)$ & $1(100)$ & $\begin{array}{l}0 \\
(0)\end{array}$ & $3(100)$ & $\begin{array}{l}1 \\
(7.1)\end{array}$ & $\begin{array}{l}13 \\
(92.9)\end{array}$ & $\begin{array}{l}6 \\
(66.7)\end{array}$ & $\begin{array}{l}3 \\
(33.3)\end{array}$ & $1(33.3)$ & $\begin{array}{l}2 \\
(66.7)\end{array}$ \\
\hline GEN 10 & $2(40.0)$ & $\begin{array}{l}3 \\
(60.0)\end{array}$ & $0(0)$ & $1(100)$ & $0(0)$ & $1(100)$ & $0(0)$ & $\begin{array}{l}3 \\
(100)\end{array}$ & $\begin{array}{l}2 \\
(14.3)\end{array}$ & $\begin{array}{l}12 \\
(85.7)\end{array}$ & $\begin{array}{l}2 \\
(22.2)\end{array}$ & $\begin{array}{l}7 \\
(77.8)\end{array}$ & $1(33.3)$ & $\begin{array}{l}2 \\
(66.7)\end{array}$ \\
\hline
\end{tabular}

$A M C=A m o x i c l a v, F X L=F l u c o x a c i l l i n, A M P=A m p i c i l l i n, C T X=C$ eftriaxone, $C X M=C$ efixime, $L E V=L$ evofloxacin, $C I P=C i p r o f l o x a c i n, O F L=O f l o x a c i n$, GEN=Gentamicin

\section{Discussion}


Results of this study indicate that there is a relatively high prevalence of asymptomatic UTI (30.0\%) in pregnant and non-pregnant women in the Limbe Health District, with a higher occurrence of gram positive bacteria. The prevalence of $30.7 \%$ in pregnant women is higher than $5.7 \%, 7.8 \%, 8.4 \%$ and $9.0 \%$, respectively reported by other investigators [1,5,8,13], close to $28.7 \%$ [23] and lower than $38.0 \%$ reported by another [24]. The high prevalence in our study may be due to differences in sample size and methods of isolation, and to the fact that UTIs are one of the most frequent and recurrent bacterial infections in women. Furthermore, the prevalence in non-pregnant women (29.3\%) was lower than $75.0 \%$ [24]. However, they studied a very small symptomatic nonpregnant population $(n=24)$, a possible reason for their very high prevalence. Generally, women suffer from urinary tract infections more often because bacteria can reach the bladder easily because of the close proximity of the vagina and anus to the urethra [6], and difficulty with hygiene due to a distended pregnant belly. During sexual activity, bacteria can be pushed into the urethra. The use of diaphragms could also be associated with the increase prevalence of asymptomatic UTI, as urine that stays in the bladder is more likely to grow bacteria and cause infection. Though we did not investigate this, it has been reported as a predisposing factor for UTI [6].

Gram-positive organisms were the most prevalent pathogens in both pregnant $87.0 \%(n=23)$ and non-pregnant $68.3 \%$ ( $n=22)$ women. This corroborates the findings in another study [24], which reported a gram positive bacterial prevalence of $60.0 \%$ in pregnant and $55.5 \%$ in non-pregnant women; another study [8], also documented a prevalence of $80.95 \%$ in pregnant women. Other researchers reported gram positive bacteria as frequent etiologic agents of UTI [7]. However, contrary to these findings, Alemu et al (67.5 \%) [13] and Ngong et al (85.4 \%) [23], identified gram negative bacteria as the most prevalent urinary tract pathogen in pregnant women.

From our findings, there was no significant difference in the etiologic profile of asymptomatic UTI in pregnant and non-pregnant women. This may imply that UTI in women of child-bearing age, can be caused by same organisms in pregnant and non-pregnant women. Though we did not investigate the role of immunosuppression in relation to infection, we are constrained to think that, immunosuppression in pregnancy, as has been previously reported [1], may not have significantly influenced occurrence of UTI in this study. S. saprophyticus occurred more in pregnant (26.2 \%) than in non-pregnant women (4.5\%), while S. aureus occurred more in non-pregnant $(22.8 \%)$ than in pregnant women (17.4\%). E coli occurred more in non-pregnant (13.6\%) than in the pregnant (8.7\%) population. The dominant isolate in this study population was $S$. aureus which is similar to a previous report [24]. They reported over $45.0 \%$ and $38.9 \%$ prevalence in pregnant and non-pregnant population. $S$. saprophyticus was the most common bacteria isolated in pregnant women; however, this does not agree with other studies $[1,5,8,13,23]$, who reported $E$. coli as the leading cause of UTI in pregnant women.

The occurrence of $N$. gonorrhoeae was noticed in pregnant $(4.3 \%, 1 / 23)$ and non-pregnant $(9.1 \%, 2 / 22)$ women. This could have been acquired through multiple mucosal sites in the lower genital tract, including the urethra, cervix, Bartholin's and Skene's glands [25]. Entrococci, Shigella and Citrobacter were among the least isolated microbes ( $2.2 \%$ each) in the study population. The low prevalence of these isolates could be a result of the sample size and the detection method used in this study.

\section{Association between Leucocyte esterase/Nitrite and asymptomatic UTI}

The occurrence of Leucocyte esterase in pregnant women (25.3\%) was higher than in non-pregnant women (9.3\%). Within the pregnant population, the association between Leucocyte esterase and asymptomatic UTI was not statistically significant $(p=0.749)$, while a significant association was noticed in nonpregnant women $(p=0.009)$. Being an indicator of immune response, its occurrence is remarkable. However, sterile pyuria is common in pregnancy, usually due to contamination by physiological vaginal discharge [26]. Sterile pyuria is a condition where a urinary dipstick test is leukocyte esterase positive with no associated positive urinary culture [27]. Pyuria could also occur as a result of the presence of non-detected bacterial and viral infections [28]. Moreover, about $58.7 \%$ (44/75) of the pregnant population was within the most sexually active group (25-35years) which could be a predisposing factor to UTI. Over $49.3 \%$ of the non-pregnant population also fell within this high sexually active group; a possible predisposing factor that could have accounted for significance in association between Leucocyte esterase and asymptomatic UTI, though Ngong et al [23] reported no statistically significant association between UTI and sexual activity.

Nitrite was virtually absent as an indicator of asymptomatic UTI in both study groups, probably because it is produced by specific gram negative microbes, notably E.coli [29], whose occurrence was low in this study. The absence of nitrite may be related to the low frequency of such specific isolates. This study reported a dominance of gram positive microbes, which mostly do not metabolize nitrate to nitrite. More so, microbial population density is also a factor related to the concentration of this waste product; and such population density may hardly occur in asymptomatic UTI cases [27].

\section{Association between asymptomatic UTI and serum creatinine level}

Serum creatinine levels in asymptomatic bacteriuria in this study population ranged from 0.2 to $1.1 \mathrm{mg} / \mathrm{dL}$ and 0.6 to $1.5 \mathrm{mg} / \mathrm{dL}$ in pregnant and non-pregnant women, respectively. The physiologic increase in glomerular filtration rate during pregnancy results in a decrease in concentration of serum creatinine, which falls by an average of $0.4 \mathrm{mg} / \mathrm{dl}$. [30]. Low serum creatinine level could also be due to low muscular activity [31]. More (13.3 \%) of the pregnant women had abnormal values of serum creatinine according to biological reference range compared to non-pregnant women (12.0\%) with abnormal results. These abnormal serum creatinine values in pregnant women could be due to renal physiologic changes that occur during pregnancy, and not necessarily a UTI [32]. This finding maybe indicative of the effect of non-bacterial factors associated with renal malfunction such as immune mediated mechanisms [33].

\section{Antimicrobial Sensitivity}

Antimicrobial resistance has increased worldwide and susceptibility patterns show substantial geographic variation as well as differences in population and environment [34]. Treatment decreases the risk of pyelonephritis, low birth weight infants, and preterm births. In our study, most isolates were sensitive to

Page $9 / 12$ 
ceftriazone and ciprofloxacin. E. coli was highly sensitive (80.0\%) to ciprofloxacin, in line with another study [35]. All three isolates of N. gonorrhoeae (1 pregnant and 2 non-pregnant women), were $100 \%$ sensitive to ciprofloxacin, and $66.7 \%$ to ceftriazone.

S. aureus was $88.9 \%$ susceptible to ceftriazone and $77.8 \%$ to ciprofloxacin. Susceptibility to ciprofloxacin is similar to another finding [36] in Nigeria, where uropathogenic $S$. aureus isolates were reported to have a $60-70 \%$ susceptibility to this antimicrobial agent.

Most isolates were completely resistant (100\%) to cefixime. This high resistance to cefixime contradicts a previous study [5], in which cefixime was reported as the most effective antimicrobial agent against UTI pathogens in pregnant women. However, their most predominant isolate was $E$. coli, a gram negative bacilli, unlike in this study, where gram positive organisms were more prevalent. This may indicate that cefixime could be more effective against gram negative bacteria than gram positive, though the few gram negative isolates in this study were still resistant to cefixime. $N$. gonorrhoeae has progressively developed resistance to antimicrobials used for the treatment of gonorrhea. Declining susceptibility to cefixime resulted in a change to the CDC treatment guidelines in 2012, to implement dual therapy with ceftriaxone and azithromycin used for treatment of gonorrhea [37]. In our study, N. gonorrhoeae was completely resistant to cefixime, ampicillin, flucloxacillin, ofloxacin and gentamicin. In another study [38] in Vientiane- Laos, this isolate was reported to be highly resistant (84.8\%) to ciprofloxacin.

\section{Conclusions}

The prevalence of asymptomatic UTI was $30.7 \%$ and $29.3 \%$ in pregnant and non-pregnant women, respectively, with gram positive bacteria as the most prevalent bacteria identified. Neisseria gonorrhoeae, Citrobacter diversus and Shigella species were most susceptible to ciprofloxacin (100\%), while Enterococci, Lactobacillus and Citrobacter diversus were most susceptible to ceftriaxone (100\%). Asymptomatic UTI had no significant effect on serum creatinine level in the study population. Leukocyte esterase was a significant indicator of asymptomatic UTI in non-pregnant women, while nitrite was not a significant indicator of asymptomatic UTI in both study groups. The use of biochemical indicators in the diagnosis of UTI in our setting should be used with caution.

\section{Abbreviations}

UTI- Urinary Tract Infection

IRB - Institutional Review Board

CLED - Cystine-Lactose Electrolyte Deficient

QC - Quality Control

CLSI - Clinical and Laboratory Standards Institute

CDC - Centers for Disease Control

\section{Declarations}

\section{Ethics approval and consent to participate}

All methods were carried out in accordance with relevant local and national regulations. An administrative authorization was obtained from the South West Regional Delegation of Public Health; ethical approval obtained from the Institutional Review Board (IRB), Faculty of Heath Sciences, University of Buea with reference number 2020/1038-12/UB/SG/IRB/FHS. A verbal authorization was obtained from the different participating health facilities. An informed consent was signed by all subjects and an informed consent by parent or guardian of subjects less than 21 years.

\section{Consent for publication}

Not applicable

\section{Availability of data and material}

All data generated and analysed during this study are included in this article

\section{Competing interest}

The authors declared that they have no competing interests

\section{Funding}

The authors received no funding. Study was financed by authors

\section{Author's contributions}

CEN collected samples, carried out laboratory investigations, and together with FAN analyzed and interpreted data, and drafted the the manuscript. 
J-FTKA, designed and supervised the study, interpreted data and reviewed the manuscript

LMN, interpreted data and reviewed manuscript

SFE, interpreted data and reviewed manuscript

FAN, analyzed and interpreted data

RNN, designed and supervised the study, interpreted data and reviewed the manuscript

\section{Aknowledgements}

We are grateful to the management of the different health facilities in the Limbe Health District, for being part of this research work. We are also thankful to the Medical Officers, Laboratory Staff and Nurses of the respective health facilities for the support, which guaranteed the realization of the objectives of this research work. We greatly appreciate the women who accepted to enroll in our study.

\section{References}

1. Tchente $\mathrm{CN}$, Ebongue CO, Chokotheu CN, Ewougo CE, Njamen TN and Mboudou E. Clinical presentation, risk factors and pathogens involved in bacteriuria of pregnant women attending antenatal clinic of 3 hospitals in a developing country: a cross sectional analytic study. BMC Pregnancy ChildB.

2019;19:143

2. El-Kashif MML. Urinary Tract Infection among Pregnant Women and its Associated Risk Factors: A Cross-Sectional Study. Biomed Pharmacol J. 2019;12(4).

3. Smaill FM, Vazquez JC. Antibiotics for asymptomatic bacteriuria in pregnancy. Cochrane Database Syst Rev. 2015;8:CD000490.

4. Onu FA, Ajah LO, Ezeonu PO, Umeora OU, Ibekwe PC, Ajah MI. Profile and microbiological isolates of asymptomatic bacteriuria among pregnant women in Abakaliki, Nigeria. Infect Drug Resist. 2015;8:231-5.

5. Mokube MN, Atashili J,Halle-Ekane GE, Ikomey GM, and Ndumbe PM. Bacteriuria amongst Pregnant Women in the Buea Health District, Cameroon: Prevalence, Predictors, Antibiotic Susceptibility Patterns and Diagnosis. Plos One. 2013;8(8): e71086.

6. Minardi D, Gianluca A, Cantoro D, Conti A, Muzzonigro G. Urinary tract infections in women: etiology and treatment options. Int J Gen Med. 2011;1(4):333-43.

7. Kimberly AK, Amanda LL. Gram-Positive Uropathogens, Polymicrobial Urinary Tract Infection, and the Emerging Microbiota of the Urinary Tract. Microbiol Spectr. 2016;4(2):10.

8. Mukherjee K, Saroj G, Vasudha CL, Babita, Bhattacharjee D, Chakroborti G. A study on asymptomatic bacteriuria in pregnancy: prevalence, etiology and comparison of screening methods. Int J Res Med Sci. 2014;2(3):1085-1091.

9. Wiles K, Bramham K, Seed PT, Nelson-Piercy C, Lightstone L, Chappell LC. Serum creatinine in pregnancy: Asystematic review. Kidney Int Rep. 2019;4:408-19.

10. Akoachere JFTK, Suylika Y, Akum NH, Esemu NS. Etiologic profile and

11. antimicrobial susceptibility of community-acquired urinary tract infection in two Cameroonian towns. BMC Res Notes. $2012 ; 5: 219$.

12. Smaill F. Asymptomatic Bacteriuria in Pregnancy. Best Pract Res Clin Obstet Gynaecol. 2007;21(3):439-50.

13. Brusch JL. Urinary Tract Infection (UTI) and Cystitis (Bladder Infection) in Females. 2020.

14. Alemu A, Moges F, Shiferaw Y, Tafess K, Kassu A, Anagaw B, Agegn A. Bacterial profile and drug susceptibility pattern of urinary tract infection in pregnant women at University of Gondar Teaching Hospital, Northwest Ethiopia. BMC Res Notes. 2012; 5:197.

15. Bryce A, Costelloe C, Wootton M, Butler CC and Hay AD. Comparison of risk factors for, and prevalence of, antibiotic resistance in contaminating and pathogenic urinary Escherichia coli in children in primary care: prospective cohort study. J Antimicrob Chemother. 2018;73(5):1359-1367.

16. Bryce A, Costelloe C, Cetal $\mathrm{H}$. Fecal carriage of antibiotic resistant Escherichia coli in asymptomatic children and associations with primary care antibiotic prescribing: a systematic review and meta-analysis. BMC Infect Dis. 2016;16:359.

17. Chin TL, MacGowan AP, Eetal KB. Prevalence of antibiotic resistance in Escherichia coli isolated from urine samples routinely referred by general practitioners in a large urban centre in South-west England. J Antimicrob Chemother. 2015;70(7):2167-9.

18. Population and house census of Cameroon, 2015. Cameroon data portal, https://cameroon.opendataforafrica.org/PHCC2015.

19. Cheesbrough M..District Laboratory Practice in Tropical Countries. Part 2, 2nd Edition. 2000, Cambridge University Press, Cambridge, United Kingdom, $434 \mathrm{pp}$

20. MulryanC. Urine testing through the use of dipstick analysis. Brit J Healthcare Assist. 2011;5(5): 243-239

21. Tazebew D, Getenet B, Selabat M, Wondewosen T. Diagnostic accuracy of rapid urine dipstick test to predict urinary tract infection among pregnant women in Felege Hiwot Referral Hospital, Bahir Dar, North West Ethiopia. BMC Res Notes. 2014;7:481.

22. Clinical and Laboratory Standards Institute. Performance standards for antimicrobial susceptibility testing: approved standard 28th ed. M100. CLinical and Laboratory Standards Institute, Wayne, PA.

23. Pfaller AM, Arthur LB, Fuchs CP. Levofloxacin Disk Potency and Tentative Interpretive Criteria for Susceptibility Tests. J Clin Microbiol. 1993;31(7): 192426. 
24. Ngong NI, Fru-Cho J,Yung MA, Akoachere JFKT. Prevalence, antimicrobial susceptibility pattern and associated risk factors for urinary tract infections in pregnant women attending ANC in some integrated health centers in the Buea Health District. BMC Pregnancy ChildB. (2021)21:673.

25. Ndamason LM, Marbou WJT, Kuete V. Urinary tract infections, bacterial resistance and immunological status: a cross sectional study in pregnant and non-pregnant women at Mbouda Ad-Lucem Hospital. Afr Health Sci. 2019;19(1):1525-1535.

26. Cheryl K Walker and Richard L Sweet Gonorrhea infection in women: prevalence, effects, screening, and management. Int J Womens Health. 2011;3: 197206.

27. Yun-Ju Lai, Te-Yao Hsu, Kuo-Chung Lan, Hao Lin, Chia-Yu Ou, Hung-Chun Fu,Ching-Chang Tsa. Asymptomatic pyuria in pregnant women during thefirst trimesteris associated with an increased risk of adverse obstetrical outcomes. Taiwanese J Obstet Gynecol. 2017;56(2017) 192-195.

28. Karikari AB, Saba CKS, Yamik D Y. Assessment of asymptomatic bacteriuria and sterile pyuria among antenatal attendants in hospitals in northern Ghana. BMC Pregnancy ChildB. 2020;20:239.

29. Wise GJ, Schlehel PN. Sterile pyuria. N Engl J Med. 2015;372:1048-54.

30. Alberto J. Martín-Rodríguez, Mikael Rhen, Keira Melican, Agenta Richter-Dahlfors. Nitrate Metabolism Modulates Biosynthesis of Biofilm Components in Uropathogenic Escherichia coli and Acts as a Fitness Factor During Experimental Urinary Tract Infection. Front Microbiol. 2020;11:26.

31. Maynard SE, Thadhani R. Pregnancy and the Kidney. J Am Soc Nephrol. 2009;20:14-22.

32. Diago CAA, Senaris JAA. Should we pay more attention to low creatinine levels? Endocrinol Diabetes Nutr. 2020;67(7):486-92.

33. Thadhani IR, Maynard ES. Maternal adaptations to pregnancy: Renal and urinary tract physiology. J Am Soc Nephrol. 2009;20(1):14-22.

34. Nasr HS, Radhakrishnan J, D'AgatiDV. Bacterial infection-related glomerulonephritis in adults. Int Soc Nephrol. 2013;83(2013):792-803.

35. Kibret M, Abera B. Antimicrobial susceptibility patterns of E. coli from clinical sources in northeast Ethiopia. Afr Health Sci. 2011;11(1) 40-45.

36. Syeda QA, Ale Z, Baquar SN, Shahjahan S, Rabia B.Resistance Pattern of Ciprofloxacin against Different Pathogens. Oman Med J. 2010;25(4) 294-298.

37. Onanuga A, Awhowho GO. Antimicrobial resistance of Staphylococcus aureus strains from patients with urinary tract infections in Yenagoa, Nigeria. J Pharm Bioallied Sci. 2012;4(3):226-30.

38. CDC. Update to CDC's Sexually transmitted diseases treatment guidelines, 2010: oral cephalosporins no longer a recommended treatment for gonococcal infections. MMWR Morb Mortal Wkly Rep 2012;61:590-4.

39. Phouangsouvanh S, Mayxay M, Keoluangkhot V, Vongsouvath M, Davong V, Dance DAB. Antimicrobial susceptibility of Neisseria gonorrhoeae isolates in Vientiane, Lao PDR. J Glob Antimicrob Resist. 2018;13:91-93. 